\title{
Avaliação de Indicadores para Estimar a Digestilidade dos Nutrientes em Novilhos Nelore Alimentados com Dietas contendo Alto Teor de Concentrado e Fontes Nitrogenadas
}

\author{
Reinaldo Cunha de Oliveira Junior ${ }^{2}$, Alexandre Vaz Pires ${ }^{3}$, Juliano José de Resende \\ Fernandes ${ }^{2}$, Ivanete Susin ${ }^{3}$, Flávio Augusto Portela Santos ${ }^{3}$, Virgílio Franco Nascimento Filho ${ }^{4}$, \\ Rafael Canonenco de Araújo 5
}

\begin{abstract}
RESUMO - Seis novilhos da raça Nelore, com peso médio inicial de $420 \mathrm{~kg}$, foram utilizados para avaliar o óxido de cromo, analisado por fluorescência de raios X, como indicador externo de digestibilidade no trato gastrintestinal. O óxido de cromo foi comparado com os indicadores internos de digestibilidade: FDN indigestível (FDNi) incubada in vitro por 144 horas e lignina detergente ácido, os quais foram comparados com a coleta total de fezes. Estimaram-se os coeficientes de digestibilidade da MS, MO, FDN, FDA, PB e EE. Os tratamentos foram: 1) farelo de soja - dieta deficiente em PDR; 2) uréia; 3) amiréia (fonte de nitrogênio não protéico de suposta liberação gradativa), ambas em dietas adequadas em PDR. Utilizou-se o bagaço de cana-de-açúcar in natura (20\% da MS) como volumoso. A estimativa da digestibilidade, utilizando o óxido de cromo, apresentou resultados similares à coleta total de fezes. O mesmo foi observado com a lignina no tratamento com farelo de soja (deficiente em PDR), mas naqueles com uréia e amiréia os coeficientes de digestibilidade foram subestimados. A FDNi subestimou a digestibilidade em todas as frações estudadas, independentemente do tratamento. A fluorescência de raios X demonstrou ser uma técnica promissora na determinação do cromo. A FDNi e a lignina não representaram a fração indigestível da dieta.
\end{abstract}

Palavras-chave: digestibilidade, indicadores, FDNi, lignina, óxido de cromo

\section{Comparison of Markers for Estimating Nutrient Digestibility in High Grain Beef Cattle Diets Varying Nitrogen Sources}

\begin{abstract}
Six Nellore bulls, with initial body weight of $420 \mathrm{~kg}$, were used to evaluate cromium oxide determined by X-ray fluorescence as an external markers of digestibility. Cromium oxide was compared to internal indicators: indigestible NDF (NDFi) incubated in vitro for 144 hours and acid detergent lignin and total feces collection. Digestibility coefficients of DM, OM, NDF, ADF, CP and EE were estimated. Experimental diets were: 1) soybean meal, in a RDP deficient diet; 2) urea; 3) starea (non protein nitrogen source supposedly of slow release), both diets with adequate RDP. Experimental diets were composed of $80 \%$ of concentrate and $20 \%$ of forage (in natura sugarcane bagasse) on dry matter basis. Digestibility estimation by using cromium oxide showed similar results with total feces collection. Lignin determination was similar to feces collection when soybean was used; however, when urea and starea were fed, the digestibility coefficient were underestimated. NDFi underestimated digestibility for all nitrogen sources. X-ray fluorescence showed to be a promising technique for cromium determination. Internal markers, NDFi incubated in vitro for 144 hours and the acid detergent lignin did not estimated the indigestible portion of the diet.
\end{abstract}

Key Words: markers, NDFi, lignin, cromium oxide, digestibility

\section{Introdução}

A digestibilidade é um dos parâmetros mais importantes para a avaliação do valor nutritivo de um alimento. A determinação da digestibilidade por meio de ensaios de alimentação, envolvendo coleta total de fezes, requer controle rigoroso das ingestões e excreções, o que a torna trabalhosa e onerosa. Além disso, em determinadas circunstâncias, este controle é praticamente impossível de ser realizado.
Várias substâncias têm sido sugeridas como indicadores de fluxo da digesta, porém nenhuma é perfeita, mas apresentam características suficientemente adequadas para fornecer dados significativos. Por essa razão, a procura de indicadores ideais constitui um dos assuntos de grande interesse na pesquisa de técnicas que facilitem os estudos em nutrição animal.

A busca por métodos mais simples para a determinação da digestibilidade conduziu ao emprego de indicadores ou marcadores que podem proporcionar uma

\footnotetext{
${ }^{1}$ Parte da tese de doutorado do primeiro autor - ESALQ/USP.

2 Doutorandos do Depto. de Zootecnia - ESALQ/USP, C.P. 09 - CEP: 13418-900, Piracicaba, SP (reinaldocoj@yahoo.com.br).

3 Professores do Depto. de Zootecnia - ESALQ/USP, C.P. 09 - CEP: 13418-900, Piracicaba, SP.

${ }^{4}$ Pesquisador do CENA/USP, C.P. 96 - CEP: 13400-970, Piracicaba, SP.

${ }^{5}$ Mestrando do Depto. de Zootecnia - ESALQ/USP.
} 
série de informações, incluindo a quantidade consumida de alimento ou nutriente específico, a taxa de passagem da digesta através de todo ou parte do trato digestivo e a digestibilidade de todo alimento ou de nutrientes específicos (Oliveira et al., 1991).

A digestibilidade in vivo é influenciada por efeitos associativos, nível de consumo, taxa de passagem e interações destes fatores e, por isso, freqüentemente é difícil imitar essas condições in vitro (Conchran et al., 1986). Nessas condições, a estimativa da digestibilidade por intermédio de indicadores pode ser desejável (Van Soest, 1994). Constituintes naturais da dieta que apresentam baixa digestibilidade têm sido utilizados como indicadores, denominados de indicadores internos, apresentando a vantagem de já estarem presentes no alimento e, de modo geral, permanecem distribuídos na digesta durante o processo de digestão e excreção (Piaggio et al., 1991).

O erro de amostragem pode ser reduzido se um componente indigestível de alta porcentagem na matéria seca puder ser encontrado. Neste sentido, tem sido sugerido que as frações fibrosas indigestíveis do alimento sejam utilizadas com este propósito (Lippke et al., 1986). Os componentes da parede celular vegetal têm sido avaliados em vários trabalhos como indicadores internos, tais como a fibra em detergente neutro (FDN) indigestível (Conchran et al., 1986; Nelson et al., 1990; Berchielli et al., 2000; Detmann et al., 2001), ressaltando a necessidade de maiores informações. O uso de lignina em detergente ácido (LDA) apresenta a vantagem de ser um método fácil e de rápida análise, barato e rotineiro em laboratórios de análise de alimentos. Recuperações positivas e incompletas foram reportadas por Muntifering (1982), Fahey \& Jung (1983) e Van Soest (1994).

Fregadolli et al. (2000) utilizaram a FDNi como indicador pela incubação ruminal de 192 horas e Ítavo et al. (2002b), pela incubação ruminal de 144 horas; ambos não obtiveram boas estimativas de digestibilidade. Segundo Piaggio et al. (1991) as variações existentes na recuperação de indicadores indigestíveis pela incubação ruminal estão associadas às perdas de partículas ocorridas pelos poros dos sacos de náilon. Outro problema apontado por Lippke et al. (1986) foi que boa parte da variabilidade dos resultados obtidos com indicadores internos indigestíveis pode ser atribuída à falta de padronização no método de determinação. O método in vitro tem a vantagem de ser mais simples e econômico, uma vez que não há necessidade de manter animais fistulados (Freitas et al., 2002).
O óxido de cromo tem sido o indicador mais amplamente utilizado para determinação da excreção fecal, apresentando as vantagens de ser barato, facilmente incorporado à dieta e analisado com relativa facilidade (Lima et al., 1980; Merchen, 1988).

Alguns trabalhos (Santos et al., 2001; Oliveira Jr. et al., 2002; Ribeiro, 1999; Imaizumi et al., 2002; Golçalves, 2000; Oliveira, 2001; Rabelo, 2002) não conseguiram atingir recuperações satisfatórias de cromo, apresentando coeficientes de digestibilidade baixos ou até negativos, não sendo possível determinar quais foram as possíveis causas. A análise utilizada nestes trabalhos foi a descrita por Fenton \& Fenton (1979), com leitura em espectrofotômetro de absorção atômica, e por Silva (1990). Estas metodologias envolvem diversas etapas de extrações químicas, implicando gasto de tempo e reagentes, podendo aumentar o erro analítico.

A técnica analítica nuclear de fluorescência de raios X com dispersão de energia (EDXRF) tem sido utilizada para a avaliação quali-quantitativa da composição química em vários tipos de amostras, de interesse agropecuário, agroindustrial, geológico e ambiental. Esta técnica, por não ser destrutiva e instrumental e por permitir a análise de vários elementos simultaneamente, de modo rápido e a baixo custo, apresenta elevado potencial de aplicação em várias áreas, onde há necessidade de correlação entre os elementos essenciais e tóxicos. Entre as vantagens da fluorescência de raios $\mathrm{X}$ para a análise química de elementos podem-se citar: (a) adaptabilidade para automação, (b) análise rápida multielementar, que é muito importante, devido à interdependência entre os micronutrientes nos sistemas biológicos, (c) preparação simplificada da amostra e (d) limite de detectabilidade dentro do exigido por muitas amostras biológicas (Nascimento Filho, 2002).

Nesse contexto, o objetivo deste trabalho foi avaliar a determinação de óxido de cromo por um novo método (fluorescência de raios X com dispersão de energia, realizada no laboratório de Instrumentação Nuclear do Centro de Energia Nuclear na Agricultura, CENA-USP) para fins de estimação da digestibilidade in vivo, bem como dos indicadores internos FDN indigestível incubada in vitro por 144 horas (6 dias) e a lignina detergente ácido, comparados à coleta total de fezes, para estimar a digestibilidade dos nutrientes, em novilhos Nelore, alimentados com três fontes de compostos nitrogenados (N): 1) farelo de soja em uma dieta deficiente em PDR; 2) uréia; 3) amiréia (fonte de nitrogênio não protéico de suposta liberação gradativa de nitrogênio), sendo as duas últimas 
dietas adequadas em PDR, utilizando o bagaço de cana-de-açúcar in natura como única fonte de volumoso (20\% da MS).

\section{Material e Métodos}

Foram utilizados seis garrotes mestiços da raça Nelore com fístula ruminal, pesando inicialmente $420 \mathrm{~kg}$, distribuídos em um delineamento em quadrado latino 3 X3 duplo, com três subperíodos de 18 dias cada, sendo 14 dias para adaptação e para coleta. Os animais foram alojados em baias individuais cobertas, do tipo tie stall (1x2,2 m), providas de bebedouros automáticos e cocho para alimentação.

Os animais foram alimentados com dietas contendo bagaço de cana-de-açúcar in natura (BIN) como volumoso (20\%) e $80 \%$ de concentrado (Tabela 1), Os tratamentos foram formulados para resultarem em dietas isoprotéicas, utilizando o programa do NRC (1996) de bovinos de corte, com o objetivo de comparar a substituição total de uma fonte de proteína verdadeira (farelo de soja), em uma dieta deficiente em PDR, por uréia ou amiréia (fonte de nitrogênio não protéico de suposta liberação gradativa de nitrogênio), ambas em uma dieta adequada em PDR.

As fontes de uréia foram: uréia (adubo convencional) e uréia extrusada, utilizando-se o milho como a fonte de amido (Amiréia 150S ${ }^{\circledR}$, Pajoara indústria e comércio, Campo Grande, MS).

O óxido de cromo foi administrado em envelopes de papel (guardanapo), contendo $5 \mathrm{~g}$ do indicador, introduzido no rúmen através da cânula ruminal, às 8 e $20 \mathrm{~h}$, totalizando $10 \mathrm{~g}$ por dia/animal, durante 10 dias consecutivos, iniciando-se no 9o dia de cada subperíodo até o último.

O fornecimento da dieta foi feito duas vezes por dia (6 e 18 h), permitindo uma sobra de 5 a 10\%. A quantidade da dieta e as respectivas sobras foram pesadas para determinação do consumo de matéria seca (MS), durante os quatro últimos dias de cada subperíodo. Amostras das dietas e das sobras, compostas por animal e período, foram coletadas e conservadas a $-10^{\circ} \mathrm{C}$ até o término do experimento para posterior análise.

A coleta total de fezes foi realizada nos quatro últimos dias de cada subperíodo, sendo estas pesadas com
Tabela 1 - Porcentagem dos ingredientes nas dietas e composição químico-bromatológica das dietas (\% da MS)

Table 1 - Proportion of the ingredient and the composition of diets (\% in dry matter)

\begin{tabular}{|c|c|c|c|}
\hline \multirow{2}{*}{$\begin{array}{l}\text { Ingredientes } \\
\text { Ingredient }\end{array}$} & \multicolumn{3}{|c|}{$\begin{array}{c}\text { Tratamentos } \\
\text { Treatments } \\
\end{array}$} \\
\hline & $\begin{array}{c}\text { FS } \\
\text { SBM } \\
\end{array}$ & $\begin{array}{l}\text { Uréia } \\
\text { Urea }\end{array}$ & $\begin{array}{r}\text { A-150S } \\
\text { Starea } \\
\end{array}$ \\
\hline $\begin{array}{l}\text { Bagaço de cana in natura (BIN) } \\
\text { In natura sugarcane bagasse }\end{array}$ & 20,5 & 20,5 & 20,5 \\
\hline $\begin{array}{l}\text { Milho moído } \\
\text { Ground corn }\end{array}$ & 27,5 & 33,2 & 30,9 \\
\hline $\begin{array}{l}\text { Polpa cítrica } \\
\text { Citrus pulp }\end{array}$ & 33,1 & 41,0 & 41,0 \\
\hline $\begin{array}{l}\text { Farelo de soja (FS) } \\
\text { Soybean meal (SBM) }\end{array}$ & 16,5 & - & - \\
\hline $\begin{array}{l}\text { Uréia } \\
\text { Urea }\end{array}$ & - & 2,46 & - \\
\hline $\begin{array}{l}\text { Amiréia (A-150S) } \\
\text { Starea }\end{array}$ & - & - & 4,78 \\
\hline $\begin{array}{l}\text { Mistura mineral } \\
\text { Mineral mix }\end{array}$ & 1,37 & 1,37 & 1,37 \\
\hline $\begin{array}{l}\text { Cloreto de potássio } \\
\text { Potass chloride }\end{array}$ & - & 0,41 & 0,41 \\
\hline $\begin{array}{l}\text { Bicarbonato de sódio } \\
\text { Sodium bicarbonate }\end{array}$ & 1,09 & 1,09 & 1,09 \\
\hline $\begin{array}{l}\text { Composição química } \\
\text { Chemical composition }\end{array}$ & & & \\
\hline $\begin{array}{l}\text { MS (\% da matéria natural) } \\
\text { DM (\% original matter) }\end{array}$ & 73,4 & 74,3 & 71,4 \\
\hline $\begin{array}{l}\text { Proteína bruta } \\
\text { Crude protein }\end{array}$ & 13,4 & 13,2 & 13,2 \\
\hline $\begin{array}{l}\text { Fibra em detergente neutro } \\
\text { Neutral detergent fiber }\end{array}$ & 28,5 & 28,5 & 28,3 \\
\hline $\begin{array}{l}\text { Fibra em detergente ácido } \\
\text { Acid detergent fiber }\end{array}$ & 23,8 & 24,2 & 24,1 \\
\hline $\begin{array}{l}\text { Matéria mineral } \\
\text { Ash }\end{array}$ & 4,3 & 3,8 & 3,8 \\
\hline $\begin{array}{l}\text { Extrato etéreo } \\
\text { Ether extract }\end{array}$ & 3,7 & 4,1 & 3,7 \\
\hline $\begin{array}{l}\mathrm{FDNi}^{2} \\
\mathrm{NDFi}\end{array}$ & 17,9 & 18,4 & 18,2 \\
\hline $\begin{array}{l}\text { Lignina } \\
\text { Lignin }\end{array}$ & 4,3 & 4,6 & 4,5 \\
\hline
\end{tabular}

${ }^{1}$ Composição no tratamento FS (farelo de soja) (Treatments composition SBM - soybean meal) $=$ NNP $=1,74 \% ; \mathrm{Ca}=0,012 \%$; $\mathrm{P}=4 \% ; \mathrm{S}=2,7 \% ; \mathrm{Cb}=750 \mathrm{ppm} ; \mathrm{I}=40 \mathrm{ppm} ; \mathrm{Mn}=1500 \mathrm{ppm}$; $\mathrm{Se}=10 \mathrm{ppm} ; \mathrm{Zn}=2250 \mathrm{ppm} ;$ Vit.A $=300000 \mathrm{UI} / \mathrm{kg} ; \mathrm{Vit} . \mathrm{D} 3=$ $20000 \mathrm{Ul} / \mathrm{kg}$; Vit.E=3500 Ul/kg; Rumensin=2\%. Tratamento uréia e A-150S (amiréia) (Treatments urea and starea) $=$ NNP $=4,35 \%$; $\mathrm{Ca}=0,012 \% ; \mathrm{P}=10 \% ; \mathrm{S}=7,1 \% ; \mathrm{Mg}=2,0 \% ; \mathrm{Cb}=750 \mathrm{ppm}$; $\mathrm{I}=40 \mathrm{ppm} ; \mathrm{Mn}=1500 \mathrm{ppm} ; \mathrm{Se}=10 \mathrm{ppm} ; \mathrm{Zn}=2250 \mathrm{ppm}$ Vit. $A=300000 \mathrm{Ul} / \mathrm{kg} ;$ Vit.D3 = $20000 \mathrm{Ul} / \mathrm{kg} ;$ Vit.E = $3500 \mathrm{UI} / \mathrm{kg}$; Rumensin $=2 \%$.

${ }^{2} \mathrm{FDNi}=$ fibra em detergente neutro indigestível, incubada por 144 horas in vitro (indigestible neutral detergent fiber, obtained after $144 \mathrm{~h}$ of in vitro). 
intervalos de doze horas, para a determinação da quantidade de fezes excretadas, em kg de matéria seca. Foi feita amostragem de 5\% das fezes totais durante os quatro últimos dias de cada subperíodo, sendo essas compostas por animal e por subperíodo. As amostras foram conservadas a $-10^{\circ} \mathrm{C}$ até o término do experimento para posterior análise.

Foram colhidas amostras de fezes (parciais), da porção final do reto, nos últimos quatro dias de cada subperíodo a cada oito horas, adiantando duas horas por dia, de maneira que se obtivesse uma amostra a cada duas horas no intervalo de 24 horas depois do término dos quatro dias do período de coleta. As amostras foram conservadas a $-10^{\circ} \mathrm{C}$ até o término do experimento, onde foram secas em estufas de ventilação forçada $\left(55-60^{\circ} \mathrm{C}\right)$ por 72 horas e processadas em moinho do tipo Wiley, primeiramente em peneira de $2 \mathrm{~mm}$ e, posteriormente, em peneira de $1 \mathrm{~mm}$. As amostras moídas foram levadas a estufa de $105^{\circ} \mathrm{C}$ por 15 horas para determinação da matéria seca (Silva, 1990) para análises de cromo, por fluorescência de raios X com dispersão de energia (EDXRF), realizadas no laboratório de Instrumentação Nuclear do Centro de Energia Nuclear na Agricultura (CENA-USP).

Conforme descrito por Korndorfer et al. (2001), parcelas de $1 \mathrm{~g}$ de fezes (parciais) foram colocadas em receptáculos especiais (polyethylene X-ray sample cups. Chemplex industries. USA) para determinação por meio de EDXRF, individualmente, correspondendo a cada animal em cada subperíodo experimental. As amostras foram agitadas durante 50 segundos com tubos de raios $\mathrm{X}$ com alvo de molibdênio (Mo) e filtro de níquel (Ni), operando a $10 \mathrm{kV} / 20 \mathrm{~mA}$. $\mathrm{Na}$ detecção de raios $\mathrm{X}$ característicos, foi utilizado um sistema de alta resolução, empregando um semicondutor de silício ativado com lítio, $\mathrm{Si}(\mathrm{Li})$, acoplado a um analisador de pulsos multicanal. Os espectros obtidos foram interpretados pelo aplicativo Analysis of X-Ray Spectra by Interative Least Square Fitting, AXIL. A fibra em detergente neutro indigestível (FDNi) foi determinada conforme Conchran et al. (1986) e a lignina em detergente ácido (LDA), segundo Goering \& Van Soest (1970).

As amostras de alimento oferecido, sobras, amostras de fezes oriundas da coleta total e parcial foram secas em estufas de ventilação forçada $\left(55-60^{\circ} \mathrm{C}\right)$ por 72 horas, depois processadas em moinho do tipo Wiley, primeiramente em peneira com crivos de $2 \mathrm{~mm}$ e posteriormente em peneira com crivos de $1 \mathrm{~mm}$, sendo estas sub-amostradas $(1 \mathrm{~g})$ e levadas à estufa de $105^{\circ} \mathrm{C}$ por 15 horas para determinação da matéria seca definitiva (Silva, 1990), para realização das análises de proteína bruta (PB), extrato etéreo (EE) e matéria mineral (MM) de acordo com a AOAC (1990). A fibra em detergente neutro $(\mathrm{FDN})$ e a fibra em detergente ácido (FDA) foram determinadas de acordo com o método de Van Soest et al. (1991), não seqüencial, utilizando amilase e sulfito de sódio nas determinações de FDN. O teor de EE nas fezes foi determinado com éter de petróleo adicionado de $10 \%$ de ácido acético, para liberar os ácidos graxos (Mattos \& Palmquist, 1974). A matéria orgânica (MO) foi obtida pela subtração da MM da MS.

A digestibilidade aparente (DA) total da MS e demais nutrientes das dietas utilizando os indicadores óxido de cromo, FDNi e LDA foi calculada pela fórmula:

$\operatorname{DA}(\%)=100-\left(\begin{array}{lll}100 \times \frac{\% \text { cromo no alimento }}{\% \text { cromo nas fezes }} & \% \frac{\% \text { do nutriente nas fezes }}{\text { do nutriente no alimento }}\end{array}\right)$

A digestibilidade aparente (DA) total da MS e demais nutrientes da dieta utilizando a coleta total de fezes foi calculada pela fórmula:

$$
\mathrm{DA}(\%)=100 \times\left(\frac{\mathrm{Kg} \text { do nutriente consumido }-\mathrm{kg} \text { do nutriente nas fezes }}{\mathrm{kg} \text { do nutriente consumido }}\right)
$$

O delineamento estatístico utilizado foi o quadrado latino 3x3 duplo com parcelas subdivididas. Os tratamentos da parcela principal foram as fontes protéicas, com e sem deficiência em PDR, e os da subparcelas, os indicadores internos (FDNi e LDA) e externo (óxido de cromo). A partir destes resultados, estimou-se a digestibilidade da MS, MO, PB, FDN, FDA e EE. Os resultados foram comparados com os obtidos por meio de coleta total de fezes e analisados pela análise da variância e comparação de médias pelo teste Tukey, por intermédio do procedimento GLM do Statistical Analysis Sistems (SAS, 1988).

\section{Resultados e Discussão}

Os resultados obtidos relativos à digestibilidade dos nutrientes pela coleta total de fezes ou estimados por intermédio dos indicadores interno (FDNi e lignina) e externo (cromo) nos respectivos tratamentos são apresentados nas Tabelas 2, 3 e 4.

Observou-se diferença significativa $(\mathrm{P}<0,05)$ para todas as frações (MS, MO, PB, FDN, FDA e EE) entre os indicadores.

As estimativas da digestibilidade aparente obtidas com o cromo não diferiram $(\mathrm{P}>0,05)$ das provenientes da coleta total de fezes para MS, MO, PB, FDN, FDA

R. Bras. Zootec., v.33, n.3, p.749-758, 2004 
e EE, independentemente do tratamento (Tabelas 2, 3 e 4). $\mathrm{O}$ cromo foi o único indicador que apresentou efeito $(\mathrm{P}<0,05)$ de tratamento nas frações FDN e FDA (Tabela 3). A redução na digestibilidade da fibra no tratamento FS era esperada, em virtude da deficiência de proteína degradável no rúmen (PDR) (Russell et al., 1992; Tedeschi et al., 2000), mas não foi confirmada pela coleta total de fezes (Tabela 3 ). Os resultados observados podem ser indicativo de que o cromo parece deixar o rúmen com os constituintes fibrosos, devido à provável fixação entre as fendas da fibra, como observado por King \& Moore (1957). Nesse sentido, Lambourne (1957) observou excreção mais lenta de cromo em ovelhas alimentadas com forragem de baixa qualidade; o mesmo foi sugerido por Lima et al. (1980). Resultados opostos a estes foram observados por Hardison et al. (1959).

$\mathrm{O}$ indicador externo cromo analisado por fluorescência de raios-X demonstrou ser uma promissora técnica de análise do cromo; metodologia (dias e horários) utilizada para coleta das amostras de fezes parciais e já bastante utilizada por diversos autores.

A fibra em detergente neutro indigestível (FDNi) incubada por 144 horas (6 dias) in vitro não diferiu apenas na estimativa da digestibilidade da fração FDN em relação à coleta total de fezes, pois subestimou $(\mathrm{P}<0,05)$ a digestibilidade das demais frações (MS, MO, PB, FDA e EE) avaliadas, independente-

Tabela 2 - Valores médios para a digestibilidade da matéria seca e matéria orgânica, obtidos pela utilização da coleta total de fezes e pelo uso de indicadores, em novilhos Nelore suplementados com fontes nitrogenadas

Table 2 - Dry matter and organic matter digestibility utilizing markers and total feces collection on Nellore bulls supplemented with nitrogenous sources

\begin{tabular}{|c|c|c|c|c|c|}
\hline \multirow[t]{2}{*}{$\begin{array}{l}\text { Indicadores } \\
\text { Markers }\end{array}$} & \multicolumn{3}{|c|}{$\begin{array}{c}\text { Tratamentos }^{2} \\
\text { Treatments }\end{array}$} & \multirow[t]{2}{*}{$\begin{array}{c}\mathrm{EPM}^{3} \\
\text { SEM }\end{array}$} & \multirow[t]{2}{*}{$\begin{array}{c}\text { Subparcela } \\
\text { Subplot }\end{array}$} \\
\hline & $\begin{array}{c}\text { FS } \\
S B M\end{array}$ & $\begin{array}{l}\text { Uréia } \\
\text { Urea }\end{array}$ & $\begin{array}{c}\text { A-150S } \\
\text { Starea }\end{array}$ & & \\
\hline \multicolumn{5}{|c|}{ Matéria seca } & \\
\hline $\begin{array}{l}\text { Coleta total de fezes } \\
\text { Total feces collection }\end{array}$ & $70,1^{\mathrm{a}}$ & $71,8^{\mathrm{a}}$ & $73,4^{\mathrm{a}}$ & 1,47 & $71,8^{\mathrm{a}}$ \\
\hline $\begin{array}{l}\text { Cromo } \\
\text { Chromium }\end{array}$ & $67,1^{\mathrm{a}}$ & $76,1^{\mathrm{a}}$ & $76,3^{\mathrm{a}}$ & 1,47 & $73,2^{\mathrm{a}}$ \\
\hline $\begin{array}{l}\mathrm{FDNi}^{1} \\
N D F i\end{array}$ & $55,8^{b}$ & $53,9^{\mathrm{c}}$ & $54,6^{\mathrm{C}}$ & 1,47 & $54,8^{\mathrm{C}}$ \\
\hline $\begin{array}{l}\text { Lignina } \\
\text { Lignin }\end{array}$ & $67,1^{\mathrm{a}}$ & $62,0^{\mathrm{b}}$ & $63,3^{b}$ & 1,47 & $64,1^{\mathrm{b}}$ \\
\hline $\begin{array}{l}\text { Parcelas } \\
\text { Plots }\end{array}$ & 65,0 & 65,9 & 66,9 & 1,38 & \\
\hline \multicolumn{6}{|c|}{$\begin{array}{l}\text { Matéria orgânica } \\
\text { Organic matter }\end{array}$} \\
\hline $\begin{array}{l}\text { Coleta total de fezes } \\
\text { Total feces collection }\end{array}$ & $73,4^{\mathrm{a}}$ & $74,6^{\mathrm{a}}$ & $76,2^{\mathrm{a}}$ & 1,29 & $74,7^{\mathrm{a}}$ \\
\hline $\begin{array}{l}\text { Cromo } \\
\text { Chromium }\end{array}$ & $70,8^{\mathrm{a}}$ & $78,4^{\mathrm{a}}$ & $78,8^{a}$ & 1,29 & $76,0^{\mathrm{a}}$ \\
\hline $\begin{array}{l}\text { FDNi } \\
N D F i\end{array}$ & $60,7^{b}$ & $58,6^{\mathrm{C}}$ & $59,4^{\mathrm{C}}$ & 1,29 & $59,5^{c}$ \\
\hline $\begin{array}{l}\text { Lignina } \\
\text { Lignin }\end{array}$ & $70,7^{\mathrm{a}}$ & $65,7^{b}$ & $68,4^{\mathrm{b}}$ & 1,29 & $68,3^{\mathrm{b}}$ \\
\hline $\begin{array}{l}\text { Parcelas } \\
\text { Plots }\end{array}$ & 68,9 & 69,3 & 70,7 & 1,22 & \\
\hline \multicolumn{6}{|c|}{$\begin{array}{l}\text { a,b,c=Letras diferentes nas colunas referem-se as médias que diferem entre si pelo teste Tukey }(\mathrm{P}<0,05) \text {; } \\
\text { as médias foram ajustadas pelos quadrados mínimos (LSMEANS) (means, in column, with the same letters, } \\
\text { did not differ [ } P>\text {. O5[ by Tukey test; the means were adjust for the least square means [LSMEANS]). } \\
{ }^{1} \mathrm{FDNi}=\text { fibra em detergente neutro indigestível, incubada por } 144 \text { horas in vitro (indigestible neutral detergent } \\
\text { fiber, obtained after } 144 \text { h in vitro). } \\
2 \mathrm{FS}=\text { farelo de soja; A-150S = amiréia (SBM = soybean meal; starea). } \\
3 \mathrm{EPM}=\text { erro-padrão da média (standard error of mean). }\end{array}$} \\
\hline
\end{tabular}

R. Bras. Zootec., v.33, n.3, p.749-758, 2004 
mente do tratamento ou média dos indicadores (subparcelas). Estes resultados estão de acordo com as observações de Ítavo et al. (2002a), os quais observaram que a FDNi apresentou valores muito baixos para a digestibilidade aparente dos nutrientes em relação aos obtidos por outros indicadores, uma vez que não realizaram a coleta total de fezes.

Paziani et al. (2000) observaram dados de digestibilidade calculados com $\mathrm{Cr}_{2} \mathrm{O}_{3}$ superiores $(\mathrm{P}<0,05)$ aos com FDN indigestível, mas não realizaram coleta total de fezes. Estes dados são similares aos observados neste experimento.

Ezequiel et al. (1999), utilizando a FDNi (incubada por $120 \mathrm{~h}$ in vitro) como indicador de digestibilidade em novilhos suplementados com farelo de soja (que possui proteína de média degradabilidade), amiréia (fonte de NNP) e farinha de subprodutos de abatedouro avícola (fonte de proteína de baixa degradabilidade), não observaram efeito de tratamento na digestibilidade da MS, PB e FDN, embora não tenham avaliado a coleta total de fezes. Esses resultados são similares aos apresentados nas Tabelas 2, 3 e 4. Entretanto, a utilização da FDNi para a estimação da digestibilidade aparente da MS e da PB resultou em subestimação (Tabelas 2 e 4).

Discordando dos dados observados por Berchielli

Tabela 3 - Valores médios para a digestibilidade da fibra em detergente neutro e fibra em detergente ácido obtidos pela utilização da coleta total de fezes e pelo uso de indicadores em novilhos Nelore suplementados com fontes nitrogenadas

Table 3 - Neutral detergent fiber and acid detergent fiber digestibility by means of markers and total feces collection on Nellore bulls supplemented with nitrogenous sources

\begin{tabular}{|c|c|c|c|c|c|}
\hline \multirow[t]{2}{*}{$\begin{array}{l}\text { Indicadores } \\
\text { Markers }\end{array}$} & \multicolumn{3}{|c|}{$\begin{array}{c}\text { Tratamentos }^{2} \\
\text { Treatments }\end{array}$} & \multirow[t]{2}{*}{$\begin{array}{c}\mathrm{EPM}^{3} \\
\text { SEM }\end{array}$} & \multirow[t]{2}{*}{$\begin{array}{c}\text { Subparcela }{ }^{4} \\
\text { Subplot }\end{array}$} \\
\hline & $\begin{array}{c}\text { FS } \\
\text { SBM }\end{array}$ & $\begin{array}{r}\text { Uréia } \\
\text { Urea }\end{array}$ & $\begin{array}{r}\text { A-150S } \\
\text { Starea }\end{array}$ & & \\
\hline \multicolumn{6}{|c|}{$\begin{array}{l}\text { Fibra em detergente neutro } \\
\text { Neutral detergent fiber }\end{array}$} \\
\hline $\begin{array}{l}\text { Coleta total de fezes } \\
\text { Total feces collection }\end{array}$ & $55,3^{a b}$ & $61,2^{\mathrm{a}}$ & $62,2^{\mathrm{a}}$ & 1,82 & $59,6^{\mathrm{a}}$ \\
\hline $\begin{array}{l}\text { Cromo } \\
\text { Chromium }\end{array}$ & $51,6^{\mathrm{Bb}}$ & $67,2^{\mathrm{Aa}}$ & $66,5^{\text {Аа }}$ & 1,82 & $61,8^{\mathrm{a}}$ \\
\hline $\begin{array}{l}\mathrm{FDNi}^{1} \\
\mathrm{NDFi}\end{array}$ & $61,1^{\mathrm{a}}$ & $58,9^{a}$ & $59,4^{\mathrm{a}}$ & 1,82 & $59,8^{a}$ \\
\hline $\begin{array}{l}\text { Lignina } \\
\text { Lignin }\end{array}$ & $51,3^{\mathrm{b}}$ & $47,5^{b}$ & $50,8^{\mathrm{b}}$ & 1,82 & $49,8^{b}$ \\
\hline Parcelas 5 & $54,8^{\mathrm{B}}$ & $58,7^{\mathrm{A}}$ & $59,7^{A}$ & 1,71 & \\
\hline \multicolumn{6}{|c|}{$\begin{array}{c}\text { Fibra em detergente ácido } \\
\text { Acid detergent fiber }\end{array}$} \\
\hline $\begin{array}{l}\text { Coleta total de fezes } \\
\text { Total feces collection }\end{array}$ & $60,9^{a}$ & $66,2^{\mathrm{a}}$ & $67,4^{\mathrm{a}}$ & 1,60 & $64,8^{\mathrm{a}}$ \\
\hline $\begin{array}{l}\text { Cromo } \\
\text { Chromium }\end{array}$ & $57,6^{\mathrm{Ba}}$ & $71,4^{\mathrm{Aa}}$ & $71,0^{\mathrm{Aa}}$ & 1,60 & $66,7^{\mathrm{a}}$ \\
\hline $\begin{array}{l}\text { FDNi } \\
N D F i\end{array}$ & $42,8^{\mathrm{b}}$ & $44,8^{\mathrm{C}}$ & $44,8^{\mathrm{C}}$ & 1,60 & $44,1^{\mathrm{C}}$ \\
\hline $\begin{array}{l}\text { Lignina } \\
\text { Lignin }\end{array}$ & $57,2^{\mathrm{a}}$ & $54,3^{b}$ & $57,1^{\mathrm{b}}$ & 1,60 & $56,2^{\mathrm{b}}$ \\
\hline $\begin{array}{l}\text { Parcelas }^{5} \\
\text { Plots }\end{array}$ & $54,6^{\mathrm{B}}$ & $59,2^{\mathrm{A}}$ & $60,1^{\mathrm{A}}$ & 1,50 & \\
\hline $\begin{array}{l}\text { a,b, } \mathrm{C}=\text { Letras diferentes } \mathrm{n} \\
\text { (means, in column, with the } \\
\mathrm{A}, \mathrm{B}=\text { =etras diferentes na } \\
\text { (means, in row, with the sa } \\
\text { quadrados mínimos (LSI } \\
{ }^{1} \mathrm{FDNi}=\text { fibra em deterge } \\
\text { fiber, obtained after } 144 \mathrm{~h} \\
2 \mathrm{FS}=\text { farelo de soja; } \mathrm{A}- \\
3 \mathrm{EPM}=\text { erro-padrão da } \\
4 \mathrm{Média} \text { das subparcelas } \\
5 \text { Média das parcelas (tra }\end{array}$ & $\begin{array}{l}\text { as refere } \\
\text { ers, did n } \\
\text { referem } \\
\text { s, did no } \\
\text { (the mear } \\
\text { o indige } \\
\text { miréia (s } \\
\text { andard er } \\
\text { lores) ( } \\
\text { s) (mean }\end{array}$ & $\begin{array}{l}\text { médias } \\
\text { p.05] by } \\
\text { édias q } \\
0.05] \text { by } \\
\text { ljusted fo } \\
\text { bubada p } \\
\text { bean me } \\
\text { n). } \\
\text { bplots [n } \\
\text { treatmen }\end{array}$ & $\begin{array}{l}\text { diferem er } \\
\text { y test. } \\
\text { ferem en } \\
y \text { test); as } \\
\text { east squar } \\
44 \text { horas } i \\
\text { rea). } \\
\text { s]). }\end{array}$ & $\begin{array}{l}\text { pelo tes } \\
\text { pelo tes } \\
\text { ias fora } \\
n s[L S M E \\
\text { (indigest }\end{array}$ & $\begin{array}{l}\text { Tukey }(\mathrm{P}<0,05) \\
\text { Tukey }(\mathrm{P}<0,05) \\
\text { justadas pelos } \\
\text { S]). } \\
\text { neutral detergent } \\
\end{array}$ \\
\hline
\end{tabular}

R. Bras. Zootec., v.33, n.3, p.749-758, 2004 
et al. (2000) quanto à estimativa da digestibilidade e Detmann et al. (2001) quanto à estimativa do consumo de animais sob pastejo, os resultados deste trabalho permitem inferir que a FDNi não deve ser utilizada em experimento que utiliza dieta com alta proporção de grãos. Conchran et al. (1986) observaram variações nas estimativas da digestibilidade em diferentes dietas utilizando a FDNi.

Confirmando os dados do atual experimento, Fregadolli et al. (2000), utilizando a fibra em detergente neutro indigestível (incubação ruminal por 192 horas) como indicador, observaram subestimação na digestibilidade ruminal e total da MS e MO, não obtendo resultados confiáveis, sugerindo que o cromo foi o melhor indicador avaliado, por apresentar menor variação (CV). Entretanto, Zeoula et al. (2001) observaram que a FDNi (incubada no rúmen por 192 horas) apresenta valores semelhantes ao da coleta total de fezes, com recuperação próxima dos $100 \%(P>0,05)$, snedo adequada para estimar a digestibilidade da MS em ovinos.

É importante salientar que os autores mencionados acima utilizaram o procedimento in situ. Neste experimento, utilizou-se o procedimento in vitro, uma vez que Piaggio et al. (1991) atribuíram as variações existentes na recuperação de indicadores indigestíveis às perdas de partículas pelos poros dos sacos de náilon. Contrariamente a esta observação, Freitas et al. (2002) verifica-

Tabela 4 - Valores médios para a digestibilidade da proteína bruta e extrato etéreo obtidos pela utilização da coleta total de fezes e pelo uso de indicadores, em novilhos Nelore suplementados com fontes nitrogenadas

Table 4 - Crude protein and ether extract digestibility utilizing markers and total feces collection on Nellore bulls supplemented with nitrogenous sources

\begin{tabular}{|c|c|c|c|c|c|}
\hline \multirow[t]{2}{*}{$\begin{array}{l}\text { Indicadores } \\
\text { Markers }\end{array}$} & \multicolumn{3}{|c|}{$\begin{array}{c}\text { Tratamentos }^{2} \\
\text { Treatments }\end{array}$} & \multirow[t]{2}{*}{$\begin{array}{c}\mathrm{EPM}^{3} \\
\text { SEM }\end{array}$} & \multirow[t]{2}{*}{$\begin{array}{c}\text { Subparcela }{ }^{4} \\
\text { Subplot }\end{array}$} \\
\hline & $\begin{array}{c}\text { FS } \\
\text { SBM }\end{array}$ & $\begin{array}{r}\text { Uréia } \\
\text { Urea }\end{array}$ & $\begin{array}{c}\text { A-150S } \\
\text { Starea }\end{array}$ & & \\
\hline \multicolumn{6}{|c|}{ Proteína bruta } \\
\hline $\begin{array}{l}\text { Coleta total de fezes } \\
\text { Total feces collection }\end{array}$ & $78,7^{\mathrm{a}}$ & $81,3^{\mathrm{a}}$ & $81,7^{\mathrm{a}}$ & 1,16 & $80,6^{\mathrm{a}}$ \\
\hline $\begin{array}{l}\text { Cromo } \\
\text { Chromium }\end{array}$ & $76,8^{\mathrm{a}}$ & $84,1^{\mathrm{a}}$ & $83,7^{\mathrm{a}}$ & 1,16 & $81,5^{\mathrm{a}}$ \\
\hline $\begin{array}{l}\text { FDNi1 } \\
N D F i\end{array}$ & $68,0^{\mathrm{b}}$ & $69,3^{\mathrm{c}}$ & $68,5^{c}$ & 1,16 & $68,6^{\mathrm{C}}$ \\
\hline \multicolumn{5}{|l|}{ Lignin } & $75,5^{\mathrm{b}}$ \\
\hline $\begin{array}{l}\text { Parcelas } \\
\text { Plots }\end{array}$ & \multicolumn{4}{|c|}{ Plots } & \\
\hline \multicolumn{4}{|c|}{ Extrato etéreo } & & \\
\hline $\begin{array}{l}\text { Coleta total de fezes } \\
\text { Total feces collection }\end{array}$ & $69,2^{\mathrm{a}}$ & $69,1^{\mathrm{a}}$ & $73,3^{a}$ & 2,05 & $70,5^{\mathrm{a}}$ \\
\hline $\begin{array}{l}\text { Cromo } \\
\text { Chromium }\end{array}$ & $66,1^{\mathrm{a}}$ & $73,8^{\mathrm{a}}$ & $76,1^{\mathrm{a}}$ & 2,05 & $72,0^{\mathrm{a}}$ \\
\hline $\begin{array}{l}\mathrm{FDNi} \\
\mathrm{NDFi}\end{array}$ & $53,2^{b}$ & $48,9^{\mathrm{C}}$ & $54,7^{\mathrm{C}}$ & 2,05 & $52,3^{c}$ \\
\hline $\begin{array}{l}\text { Lignina } \\
\text { Lignin }\end{array}$ & $65,5^{\mathrm{a}}$ & $58,3^{\mathrm{b}}$ & $64,4^{\mathrm{b}}$ & 2,05 & $62,7^{\mathrm{b}}$ \\
\hline $\begin{array}{l}\text { Parcelas } \\
\text { Plots }\end{array}$ & 63,5 & 62,5 & 67,1 & 1,93 & \\
\hline $\begin{array}{l}\text { a,b,c=Letras diferentes } \\
\text { as médias foram ajustad } \\
\text { not differ }[P>05] \text { by Tukey } \\
{ }^{1} \mathrm{FDNi}=\text { fibra em deterg } \\
\text { fiber, obtained after } 144 \\
{ }^{2} \mathrm{FS}=\text { farelo de soja; } \mathrm{A}- \\
{ }^{3} \mathrm{EPM}=\text { erro-padrão da } \\
{ }^{4} \mathrm{Média} \text { das subparcela } \\
{ }^{5} \text { Média das parcelas (tr }\end{array}$ & $\begin{array}{l}\text { s refere } \\
\text { juadrad } \\
\text { eans wer } \\
\text { o indige } \\
\text { niréia (s } \\
\text { ndard er } \\
\text { ores) ( }\end{array}$ & $\begin{array}{l}\text { médias } \\
\text { os (LSN } \\
\text { pr the lea } \\
\text { ubada p } \\
\text { ean mea } \\
\text { n). } \\
\text { ubplots }\end{array}$ & $\begin{array}{l}\text { liferem en } \\
\text { S) (Means, } \\
\text { lare means } \\
4 \text { horas in } \\
\text { ea). }\end{array}$ & $\begin{array}{l}\text { pelo tes } \\
\text { lumn, with } \\
\text { IEANS]). } \\
\text { (indigest }\end{array}$ & $\begin{array}{l}\text { ukey }(\mathrm{P}<0,05) \text {; } \\
\text { same letters, did } \\
\text { neutral detergent }\end{array}$ \\
\hline
\end{tabular}

R. Bras. Zootec., v.33, n.3, p.749-758, 2004 
ram que as estimativas de produção fecal obtidas com o uso da FDNi incubada in vitro e FDNi incubada in situ foram sub e superestimadas, respectivamente, e, portanto, recomendaram a utilização da FDA obtida in vitro. Outro problema é que, segundo Lippke et al. (1986), boa parte da variabilidade dos resultados obtidos com indicadores internos indigestíveis pode ser atribuída à falta de padronização no método de determinação.

A lignina em detergente ácido (LDA) proporcionou estimativas da digestibilidade de todas as frações (MS, MO, PB, FDN, FDA e EE) que não diferiram $(\mathrm{P}>0,05)$ às da coleta total de fezes no tratamento FS (deficiente em PDR), mas subestimou a digestibilidade de todas as mesmas frações nos tratamentos uréia e amiréia (PDR ajustada). Estes dados permitem inferir, em dietas ajustadas em PDR (uréia e amiréia), em que se espera maior digestibilidade da fração fibrosa da dieta, sobre a possível contribuição para redução da recuperação da LDA nas fezes; fato comprovado quando se utilizou cromo como indicador (Tabela 3).

Os resultados obtidos no atual experimento estão de acordo com Muntifering (1982), Fahey \& Jung (1983) e Van Soest (1994), os que reportaram recuperações positivas e incompletas da lignina - indicador que deve ser utilizado com cautela, sendo viável quando se tem informação de sua recuperação (Merchen, 1988), o que fica evidente neste experimento.

As alterações na recuperação da lignina também podem ter efeito de raça segundo Lançanova et al. (2000), que observaram recuperação do indicador LDA de apenas $83 \%$ para os animais da raça Nelore, ficando os valores de recuperação do indicador para as demais raças avaliadas (Zebuínas e Taurinas) próximos a 98\%. Os autores concluíram que a lignina em detergente ácido foi eficiente na estimativa da digestibilidade do EE, PB e da fibra.

Silva et al. (2002), utilizando a LDA como indicador de digestibilidade em novilhos suplementados com farelo de soja (que possui proteína de média degradabilidade), amiréia (fonte de NNP) e farinha de subprodutos de abatedouro avícola (fonte de proteína de baixa degradabilidade), não observaram alterações na digestibilidade da MS, MO, PB, FDN e FDA entre os tratamentos. Esses resultados foram similares aos observados no presente estudo, no tocante ao efeito de tratamento, mas a utilização de LDA acarretou subestimação dos coeficientes de digestibilidade nos tratamentos com NNP (uréia e amiréia) em relação à coleta total de fezes (Tabelas 2, 3 e 4).

Thonney et al. (1979) e Valadares Filho et al. (1985) observaram estimativa da digestibilidade total utilizando-se o cromo ou o método de coleta total, em média 24\% superior à obtida pela lignina. Estes dados estão próximos dos observados no presente experimento, onde o coeficiente de digestibilidade da MS por coleta total de fezes e pelo cromo foi de 15 e $20 \%$ superior aos de LDA, respectivamente, nos tratamentos com nitrogênio não protéico (uréia e amiréia), discordando, porém, dos observados no tratamento FS.

Segundo Fahey \& Jung (1983), as prováveis razões para a baixa recuperação da lignina são: digestão verdadeira; digestão aparente obtida pela formação de complexos lignina-carboidratos solúveis que passam pelo rúmen e, provavelmente, pelo intestino como polímeros e não são recuperados no resíduo de fibra das fezes; destruição parcial da lignina fecal pelos reagentes utilizados nos métodos analíticos; e diferenças químicas e/ou físicas entre alimentos e fezes nos materiais naturais empiricamente definidos como lignina.

\section{Conclusões}

O indicador externo cromo analisado por fluorescência de raios-X proporcionou a obtenção de estimativas relativas à digestibilidade, que não diferiram estatisticamente das da coleta total de fezes.

O indicador interno FDNi incubada por 144 horas in vitro não representou a fração indigestível da dieta (alta proporção de concentrado), necessitando de mais informações de sua recuperação na dieta em questão para se viabilizar o seu uso.

O sucesso do uso lignina como indicador interno de digestibilidade parece estar relacionado com a dieta, ou seja, em dieta com PDR adequada (via NNP) subestimou a digestibilidade, mas em dietas com deficiência de PDR e fonte de proteína verdadeira (farelo de soja), apresentou boas estimativas.

\section{Literatura Citada}

ASSOCIATION OF OFFICIAL ANALYTICAL CHEMISTS AOAC. Official methods of analysis. 12.ed. Washington, D.C.: 1990. 1015p.

BERCHIELLI, T.T.; ANDRADE, P.; FURLAN, C.L. Avaliação de indicadores internos em ensaios de digestibilidade. Revista Brasileira de Zootecnia, v.29, p.830-833, 2000.

COCHRAN, R.C.; ADANS, D.C.; WALLACE, J.D. et al. Predicting digestibility of different diets with internal markers: evaluation of four potential markers. Journal of Animal Science, v.63, p.1476-1483, 1986.

DETMANN, E.; PAULINO, M.F.; ZERVOUDAKIS, J.T. et al. Cromo e indicadores internos na determinação do consumo de

R. Bras. Zootec., v.33, n.3, p.749-758, 2004 
novilhos mestiços suplementados, a pasto. Revista Brasileira de Zootecnia, v.30, p.1600-1609, 2001.

EZEQUIEL, J.M.B.; MENDES, A.R.; SILVA, L.D.F. et al. Estimativa da digestibilidade através da FDN indigestível de rações contendo dois níveis de casca de soja e diferentes fontes protéicas em novilhos mestiços. In: REUNIÃO ANUAL DA SOCIEDADE BRASILEIRA, 36., 1999, Porto Alegre. Anais... Porto Alegre: Sociedade Brasileira de Zootecnia, 1999. Seção de nutrição de ruminantes (CD-Rom).

FAHEY, G.C.; JUNG, H.G. Lignin as a marker in digestion studies - a review. Journal of Animal Science, v.75, p.220-225, 1983.

FENTON, T.W.; FENTON, E. An improved procedure for determination of chromic oxide in food and feces. Canadian Journal of Animal Science, v.59, p.631-634, 1979.

FREGADOLLI, F.L.; ZEOULA, L.M.; KASSIES, M. et al. Avaliação de indicadores no estudo da digestibilidade dos alimentos. In: REUNIÃO ANUAL DA SOCIEDADE BRASILEIRA DE ZOOTECNIA, 37., 2000, Viçosa, MG. Anais... Viçosa, MG: Sociedade Brasileira de Zootecnia, 2000.(CDROM)

FREITAS, D.; BERCHIELLI, T.T.; SILVEIRA, R.N. et al. Produção fecal e fluxo duodenal de matéria seca e matéria orgânica estimados por meio de indicadores. Revista Brasileira de Zootecnia, v.31, n.3, p.1521-1530, 2002.

GOERING, H.K.; Van SOEST, P.J. Forage fiber analysis (Apparatus, reagents, procedures and some applications). Agricultural Handbook, Washington, D.C.: Agricultural Research Service, 1970. p.19.

GONÇALVES, J.R.S. Efeito da substituição do grão de milho pelo de milheto (Pennisetum americanum), em dietas de bovinos de corte em confinamento. Piracicaba: Escola Superior de Agricultura "Luiz de Queiroz", 2000. 70p. Dissertação (Mestrado em Ciência Animal e Pastagens) Escola Superior de Agricultura “Luiz de Queiroz”, 2000.

HARDISSON, W.A.; LINKOUS, W.N.; ENGEL, R.W. et al. Observation on the use of chromic oxide for estimating the fecal output of dairy animals. Journal of Dairy Science, v.42, p.345-352, 1959.

IMAIZUMI, H.; SANTOS, F.A.P.; PIRES, A.V. et al. Avaliação de diferentes fontes e teores de proteína degradável no rúmen sobre o desempenho e parâmetros ruminais e sanguíneos de vacas Holandesas em final de lactação. Acta Scientiarum, v.24, n.4, p.1031-1037, 2002.

ÍTAVO, L.C.V.; SILVA, F.F.; FERREIRA, C.C.B. et al. Comparação de indicadores e metodologia de coleta para estimativas de produção fecal e fluxo da digesta em bovinos. Revista Brasileira de Zootecnia, v.31, n.4, p.1833-1839, 2002a.

ÍTAVO, L.C.V.; VALADARES FILHO, S.C.; SILVA, F.F. et al. Consumo, degradabilidade ruminal e digestibilidade aparente de fenos de gramíneas do gênero cynodon e rações concentradas utilizando indicadores internos. Revista Brasileira de Zootecnia, v.31, n.2, p.1024-1032, 2002b.

KING, K.W.; MOORE, E.C. Density and size as factors a affecting passage rate of ingest in the bovine and human digestive tracts. Journal of Dairy Science, v.40, p.528536, 1957.

KORNDORFER, C.M.; ABDALLA, A.L.; BUENO, I.C.S. et al. Estudo da cinética digestiva em ovinos alimentados com braquiária e alfafa, usando a técnica de fluorescência de raios X. Veterinária Notícias, v.7, p.113-121, 2001.

LANÇANOVA, J.A.C.; OLIVEIRA, M.D. S.; PACOLA, L.J. et al. Digestibilidade aparente do extrato etéreo, da proteína bruta e dos componentes da parede celular de uma ração completa, com zebuinos e taurinos. In: REUNIÃO ANUAL
DA SOCIEDADE BRASILEIRA DE ZOOTECNIA, 37., 2000, Viçosa, MG. Anais... Viçosa, MG: Sociedade Brasileira de Zootecnia, 2000. CD ROM

LIMA, M.A.; VIANA, J.A.C.; RODRIGUES, N.M. et al. O uso do óxido crômico para estimar a excreção fecal de novilhos zebus em pastejo. Revista Brasileira de Zootecnia, v.9, p.188-202, 1980.

LIPPKE, H.; ELLIS, W.C.; JACOBS, B.F. Recovery of indigestible fiber from feces of sheep and cattle on forage diets. Journal of Dairy Science, v.69, p.403-412, 1986.

MATTOS, W.; PALMQUIST, D.L. Increased polyunsaturated fatty acid yields in milk of cows fed protected fat. Journal of Dairy Science, v.57, p.1050-1054, 1974.

MERCHEN, N.R. Digestion, absorption and excretion in ruminants. In: CHURCH, D.C. (Ed.) The ruminant animal: digestive physiology and nutrition. New Jersey: Prentice Hall, 1988. p.171-201.

MUNTIFERING, R.B. Evaluation of various lignin assays for determining ruminal digestion of roughages by lambs. Journal of Animal Science, v.55, p.432-438, 1982.

NASCIMENTO FILHO, V.F. Técnicas analíticas nucleares de fluorescência de raios X por dispersão de energia (EDXRF) e por reflexão total (TXRF), 1999. Disponível em http://web.cena.usp.br/apostilas/Virgilio/cen-5723/ EDXRF TXRF.doc. Acesso em: 20 jun. 2002.

NATIONAL RESEARCH COUNCIL - NRC. Nutrient requirements of beef cattle. 7.ed. Washington, D.C.: National Academy Press, 1996. 242p.

NELSON, M.L.; MOTJOPE, L.; FINLEY, J.W. et al. Ash free indigestible acid detergent fiber as an internal marker to estimate digestibility wither grazing ruminants. Journal Range Management, v.43, n.3, p.224-229, 1990.

OLIVEIRA, S.G. Utilização de fontes de gordura em dietas com diferentes níveis de fibra para vacas em lactação. Piracicaba: Escola Superior de Agricultura “Luiz de Queiroz”, 2001. 75p. Dissertação (Mestrado em Ciência Animal e Pastagens) - Escola Superior de agricultura “Luiz de Queiroz”, 2001.

OLIVEIRA JR., R.C.; SUSIN, I.; PIRES, A.V. et al. Desempenho de cabras em lactação alimentadas com grão de soja. Acta Scientiarum, v.24, n.4, p.1113-1118, 2002.

OLIVEIRA, D.E.; MEDEIROS, S.R.; AROEIRA, L.J.M. et al. Padrão da excreção fecal de cromo utilizado como indicador externo para estimativa da produção fecal. In: REUNIÃO ANUAL DA SOCIEDADE BRASILEIRA DE ZOOTECNIA, 38., 2001, Piracicaba. Anais... Piracicaba: Sociedade Brasileira de Zootecnia, 2001.

OLIVEIRA, R.F.M.; FONTES, C.A.A.; SILVA, J.F.C. Estudo da recuperação fecal do $\mathrm{Cr}_{2} \mathrm{O}_{3}$ e dos indicadores internos CIA e CIDA e lignina em períodos de coleta de dois a sete dias, em bovinos. Revista da Sociedade Brasileira de Zootecnia, v.20, p.522-531, 1991.

PAZIANI, S.F.; BERCHIELLI, T.T.; ANDRADE, P. et al. Digestibilidade de rações à base de milho desintegrado com palha e sabugo em diferentes granulometrias. In: REUNIÃO ANUAL DA SOCIEDADE BRASILEIRA DE ZOOTECNIA, 37., 2000, Viçosa, MG. Anais... Viçosa, MG: Sociedade Brasileira de Zootecnia, 2000.

PIAGGIO, L.M; PRATES, E.R.; PIRES, F.F. et al. Avaliação das cinzas insolúveis em ácido, fibra, em detergente ácido indigestível e lignina em detergente ácido indigestível com indicadores internos da digestibilidade. Revista da Sociedade Brasileira de Zootecnia, v.20, p.306-312, 1991.

RABELO, M.M.A. Efeitos de fontes e neveis de fibra íntegra, em dietas contendo bagaço de cana-de-açúcar tra-

R. Bras. Zootec., v.33, n.3, p.749-758, 2004 
tado sob pressão e vapor, sobre a digestibilidade, desempenho e comportamento ingestivo de bovinos de corte. Piracicaba: Escola Superior de Agricultura "Luiz de Queiroz”, 2002. 61p. Dissertação (Mestrado em Ciência Animal e Pastagens) - Escola Superior de Agricultura "Luiz de Queiroz”, 2002.

RIBEIRO, C.V.M. Efeito da substituição do grão de milho pelo de milheto (Pennisetum americanum) na dieta de vacas em lactação. Piracicaba: Escola Superior de Agricultura “Luiz de Queiroz”, 1999. 67p. Dissertação (Mestrado em Ciência Animal e Pastagens) - Escola Superior de Agricultura "Luiz de Queiroz", 1999.

RUSSEL, J.B.; O‘CONNOR, J.D.; FOX, D.G. et al. A net carbohydrate and Protein System for evaluating cattle diets: I. Ruminal fermentation. Journal of Animal Science, v.70, p.3551-3561, 1992.

SANTOS, F.A.P.; MENDES JR., M.P.; SIMAS, J.M.C. et al. Processamento do grão de milho e sua substituição parcial por polpa de citros peletizada sobre o desempenho, digestibilidade de nutrientes e parâmetros sanguíneos de vacas leiteiras. Acta Scientiarum, v.23, n.4, p.923-931, 2001.

STATISTICAL ANALYSES SYSTEMS - SAS. SAS/STAT Institute - User's guide. Cary: 1988.

SILVA, D.J. Análise de alimentos: métodos químicos e biológicos. Viçosa, MG: Universidade Federal de Viçosa, 1990. 166p.

TEDESCHI, L.O.; FOX, D.G.; RUSSELL, J.B. Accounting for the effects of a ruminal nitrogen deficiency within the structure of the Cornell Net Carbohydrate and Protein System. Journal of Animal Science, v.78, p.1648-1658, 2000.

THONNEY, M.L.; DUHAIME, D.J.; MOE, P.W. et al. Acid insoluble ash and permenganate lignin as indicators to determine digestibility of cattle rations. Journal of Animal Science, v.49, p.1112-16, 1979.
VALADARES FILHO, S.C.; SILVA, J.F.C.; LEÃO, M.I. et al. Óxido crômico e lignina na determinação dos fluxos de matéria seca abomasal, ileal e fecal em bovinos e bubalinos. Revista da Sociedade Brasileira de Zootecnia, v.14, p.565-574, 1985.

Van SOEST, P.J. Nutrition ecology of the ruminant. 2.ed. Ithaca: Cornell University Press, 1994. 476p.

Van SOEST, P.J.; ROBERTSON, J.B.; LEWIS, B.A. Methods for dietary fiber, neutral detergent fiber, and nonstarch polysaccharides in relation to animal nutrition. Journal of Dairy Science, v.74, p.3583, 1991.

ZEOULA, L.M.; DIAN, P.H.M.; CALDAS NETO, S.F. et al. Avaliação de indicadores internos em ensaios de digestibilidade para ruminantes. In: REUNIÃO ANUAL DA SOCIEDADE BRASILEIRA DE ZOOTECNIA, 38., 2001, Piracicaba. Anais... Piracicaba: Sociedade Brasileira de Zootecnia, 2001. CD ROM 